\title{
ETNOGRAFÍA Y EXTENSIÓN UNIVERSITARIA. \\ CONOCER E INTERVENIR EN UN CONFLICTO POR HÁBITAT EN LA \\ PLATA, ARGENTINA
}

Soledad Balerdi ${ }^{1}$

\section{Introducción}

Este artículo explora de modo situado las posibilidades de una etnografía que se articule con otras formas de construcción de conocimiento en el campo. En particular, aborda la articulación entre etnografía y extensión universitaria en un conflicto habitacional que tuvo lugar en un barrio popular de la ciudad de La Plata, provincia de Buenos Aires (Argentina) entre los años 2014 y 2015.

La extensión es una función universitaria orientada a la vinculación de la universidad con distintos actores sociales del ámbito local, con el fin de intervenir en problemáticas a las que las disciplinas académicas y sus comunidades pueden contribuir. Es una práctica que en el ámbito universitario argentino ha ido ganando en los últimos años cada vez mayor relevancia e institucionalización. Sin embargo, conserva todavía cierto lugar secundario en comparación con las otras dos funciones tradicionales de la universidad, la investigación y la docencia, que aún se piensan como los especacios privilegiados de producción y transmisión del conocimiento (Pinedo, 2019).

La tesis que este artículo busca sostener empíricamente es la de que la producción de conocimiento sobre el conflicto estudiado se dio en la articulación misma entre etnografía y extensión.

Este conflicto habitacional que será objeto del artículo estuvo motivado por un proyecto de relocalización de viviendas, a causa de una obra de infraestructura hidráulica sobre un arroyo que atraviesa la periferia platense. La obra fue implementada por el gobierno provincial con motivo de una trágica inundación acontecida en la ciudad de La Plata en el año 2013. La misma supuso, como veremos, la canalización y ensanchamiento del arroyo, y como consecuencia, la relocalización de cientos de viviendas de barrios populares que se asientan en sus márgenes.

\footnotetext{
${ }^{1}$ Universidad Nacional de La Plata, Argentina. Email: soledadbalerdi@gmail.com ORCID: https://orcid.org/0000-0001-6631-9805
} 
El artículo inicia con una primera parte en la que presento este conflicto y doy cuenta de cómo se gestó la posibilidad de seguirlo desde un doble rol: como etnógrafa pero también como miembro de uno de los actores que intervino en él, un proyecto de extensión universitaria. A partir de ello presento el enfoque teórico desde el que llevé adelante la investigación, en base a lo que llamé "seguir el conflicto" en el cruce entre etnografía y pragmatismo. La sociología pragmática, especialmente del campo de estudios sobre acciones colectivas y construcción de denuncias (Boltanski, 2000; Cefaï, 2009, 2011) ofrecerá un arsenal teórico sumamente interesante para abordar este conflicto que se trama en torno a un reclamo por hábitat, y que es llevado adelante por una red de actores que no existía previamente como actor colectivo sino que se constituye al calor del conflicto mismo.

En una segunda parte, el artículo aborda las modalidades de intervención extensionista en el conflicto. En este sentido se ocupa de reponer empíricamente las relaciones que se dan "en las fronteras porosas entre universidad y territorio" (Pinedo, 2020: 1) en el marco de la extensión en un caso concreto, y para ello realiza una descripción de la dinámica que cobró el accionar del proyecto de extensión en el conflicto, concentrándose en un evento particular del mismo: un relevamiento sobre las condiciones habitacionales del barrio.

Por último, sobre la base de lo presentado en las dos secciones anteriores, el artículo explora en la tercera parte una de las modalidades en que se da la articulación entre etnografía y extensión: la escritura. El rol de la escritura en la intervención extensionista, tanto como en el registro de las actividades cotidianas y en la elaboración de interpretaciones sobre la práctica de extensión, se constituye en un punto de encuentro con la etnografía, la cual también se plasma en "cadenas de escrituras" (Cefaï, 2013) que van de la nota de campo, a la descripción y al texto etnográfico.

Por ello aquí la etnografía será entendida como enfoque y como texto, y no sólo como método de construcción de datos (Guber, 2011; Peirano, 2014). Esto quiere decir que la etnografía permite elaborar una interpretación sobre las tramas estudiadas, fundada en los datos de campo y en el diálogo entre esos datos y diversas teorías y resultados de otras investigaciones sociales. Y de ese modo también produce teoría. Por otra parte, la extensión no será concebida de modo instumental, únicamente como la vía de acceso al campo (que sería luego estudiado y comprendido etnográficamente), sino como forma de estar y hacer en él que produce también conocimiento social situado. 


\section{Primera parte: la emergencia de un conflicto habitacional}

En abril de 2013, La Plata fue testigo de una terrible inundación que se produjo en cuestión de horas, afectó a toda la ciudad y sus alrededores, y ocasionó la muerte de un centenar de personas. Si bien la causa inmediata de la inundación fue la velocidad y magnitud de las precipitaciones que cayeron aquel 2 de abril, las interpretaciones posteriores atribuyeron el desastre a la falta de obras hidráulicas adecuadas en las cuencas y arroyos de la zona que permitieran el escurrimiento y circulación del agua. Uno de los arroyos que más desbordó durante la tormenta fue El Gato, habitualmente plagado de desechos y vegetación, y sobre cuyos márgenes se asientan muchas viviendas de la periferia.

Ante este diagnóstico, el Ministerio de Infraestructura de la provincia de Buenos Aires comenzó a desarrollar una obra millonaria que suponía, entre otras cosas, el ensanchamiento y revestimiento del arroyo El Gato en toda su extensión, para la prevención de futuras inundaciones. El plan de obra se complementaba con un proyecto de relocalización de las cientos de viviendas que se ubicaban sobre los márgenes del arroyo y que debían ser removidas para la ampliación del canal.

Las Quintas, un barrio de la periferia de la ciudad de La Plata en el que habita alrededor de una decena de familias migrantes, sería uno de esos barrios que se vería afectado por la relocalización. Ocupando unas pocas manzanas de trazado regular pero interrumpidas al fondo por el curso zigzagueante del arroyo El Gato, el barrio se ubica a unos seis kilómetros del centro de la ciudad. En la esquina de acceso, un pilar colorido con la imagen de la Virgen María separa dos sectores diferenciados del barrio: por un lado, el de los habitantes de origen qom $^{2}$ nacidos en la provincia de Chaco (al norte de Argentina), y por otro el habitado por familias provenientes de Paraguay. Estos dos sectores del barrio, cuyas diferencias para un observador externo serían imperceptibles, están sin embargo bien delimitados para sus pobladores.

El origen de Las Quintas se remonta a principios de los años 2000. Las primeras familias qom en llegar migraron a La Plata en busca de trabajo. Supieron de la existencia de unos terrenos desocupados junto al arroyo, y progresivamente fueron instalándose allí mediante la autoconstrucción de sus viviendas con chapa y madera. Con los años, reproduciendo el flujo migratorio hacia las grandes ciudades, nuevas

\footnotetext{
${ }^{2}$ Población indígena originaria del norte de Argentina, principalmente de las regiones de Chaco y Formosa. Ver Wright (2008).
} 
familias del Chaco arribaron al barrio, conducidas por las redes de parentesco. Las primeras casillas fueron siendo reemplazadas en muchos casos por pequeñas construcciones de ladrillos, dando al barrio su morfología actual. El sector paraguayo se fue conformando con algunos años de posterioridad, a partir del alquiler o la compra de viviendas a habitantes anteriores.

En la actualidad, Las Quintas es un barrio que aún y a pesar de su relativa antigüedad -en comparación con otros asentamientos de la región- presenta condiciones precarias de infraestructura. A las calles de tierra, la inexistencia de sistemas cloacales, y las conexiones eléctricas deficitarias se suma la recurrente falta de recolección de residuos, y su cercanía a este arroyo contaminado e inundable.

Será precisamente este arroyo el foco de la gran obra de infraestructura hidráulica que desarrollará la provincia a partir del año 2014 y que motivará la emergencia de un conflicto por hábitat en Las Quintas. Como veremos, la obra comenzó a desarrollarse sin que los habitantes fueran informados oficialmente respecto a sus consecuencias para el barrio. Cuando las máquinas excavadoras comenzaron a trabajar sobre el arroyo, removiendo tierra y avanzando ya a pocas cuadras de Las Quintas, este escenario de desinformación e incertidumbre motivaría la emergencia de un reclamo ante los funcionarios del Ministerio.

\section{Etnografia desde un doble rol}

Conocí Las Quintas en el año 2011, a partir de mi inserción en un proyecto de extensión universitaria. Este proyecto, al que había sido invitada por colegas de la universidad, trabajaba con las familias qom del barrio desde el año 2009. Sus miembros éramos en su mayoría docentes, graduados y estudiantes de la carrera de Sociología, aunque también parte del equipo provenía de Psicología, Ciencias de la Educación, Antropología y Trabajo Social de la Universidad Nacional de La Plata (UNLP). Las tareas a las que nos abocábamos en el barrio consistían centralmente en el acompañamiento de la inserción escolar de los niños y niñas y el desarrollo de talleres de literatura infantil, de psicología comunitaria, de producción audiovisual con jóvenes y de tejido con mujeres.

En nuestras idas semanales al barrio, desarrollábamos estos talleres en una pequeña edificación a la que llamábamos "Salón Comunitario". Entre mates y charlas, íbamos conociendo a los vecinos y sus historias. Sabíamos que desde sus orígenes, los 
habitantes del sector qom con quienes trabajábamos habían luchado sin éxito por la obtención de la titularidad de esas tierras sobre las que se asentaban. Sabíamos también que habían conformado una Asociación civil ante el Instituto Nacional de Asuntos Indígenas (como paso necesario para la regularización dominial), pero que dicha figura había perdido vigencia y que los pocos intentos de realizar asambleas convocadas por algunos referentes de la Asociación siempre se veían frustrados por la inasistencia de los vecinos. De hecho, desde mi ingreso al Proyecto, nunca logré comprender cabalmente el derrotero de la organización, porque los relatos sobre su historia siempre eran breves, parciales y confusos. Circulaban además sospechas sobre y entre los referentes, especialmente cuando llegaban recursos al barrio y se desataban los desacuerdos respecto a la equidad o inequidad de su distribución.

En este marco, en nuestro trabajo semanal con los miembros del Proyecto fuimos elaborando el diagnóstico de que, tal como sucede en otros casos estudiados por la bibliografía (Auyero y Swistún, 2008), las disputas y conflictos interpersonales entre los vecinos de Las Quintas contribuían a desalentar o dificultar la consolidación de acciones colectivas. Este diagnóstico sustentaba -desde una mirada no libre de ciertas pretensiones iluministas- uno de los objetivos que atribuíamos a las actividades de extensión que desarrollábamos en el Salón Comunitario del barrio: fomentar la apropiación de ese espacio común y la consolidación de lazos de vecindad y amistad que condujeran a limar posibles asperezas en los vínculos existentes.

Las actividades de extensión que llevábamos a cabo en el barrio eran sostenidas a partir del trabajo voluntario de los integrantes del proyecto, y del financiamiento otorgado por la Universidad para viáticos y otros gastos cotidianos en el desarrollo de los talleres. Según el reglamento de extensión de la UNLP, los proyectos tienen una duración anual, por lo que para garantizar una intervención continuada, era necesario presentarse año tras año a la convocatoria a partir de la cual se seleccionarían aquellos que serían aprobados y financiados por la Universidad. Bajo este formato, se hacía necesario repensar, formular y escribir objetivos y actividades a realizar en la intervención. En términos generales compartíamos una concepción de la extensión universitaria entendida como un diálogo con los intereses, conocimientos y necesidades de las personas en cuyo territorio interveníamos ${ }^{3}$. En este marco, los dos objetivos que

\footnotetext{
${ }^{3} \mathrm{Si}$ en términos generales podemos decir que la función de la extensión es la vinculación de la universidad con la sociedad, esta afirmación bastante ambigua abriga en sí concepciones y formas de la práctica extensionista muy disímiles. De modo esquemático, podrían identificarse dos grandes
} 
sosteníamos con regularidad eran el de promover el acceso efectivo al derecho a la educación de los niños y jóvenes del barrio, y el de fortalecer los espacios de encuentro de la comunidad.

La fundamentación sobre la que los miembros del Proyecto basábamos estos objetivos refería a la extrema vulnerabilidad de la población, debido a -como sostenían los textos que presentábamos a estas convocatorias- "su triple condición de pobre, migrante interna y perteneciente a un pueblo originario". Esto se conjugaba con la percepción antes mencionada de que no había en el barrio una trama consolidada que garantizara la organización colectiva -algo que desde nuestra óptica era fundamental para la lucha por (y la obtención de) mejores condiciones de vida para sus habitantes-.

Estos objetivos generales debían traducirse a tareas y acciones prácticas que nos permitieran concretizarlos. Para ello, los objetivos específicos de las actividades realizadas suponían, entre otras cosas, habilitar para los niños y jóvenes que participaban de los talleres el acceso a herramientas informáticas, el fortalecimiento de la lectura y la escritura, de la expresión artística, el acompañamiento de las familias en la escolaridad. Además, como mencioné, se buscaba que el Salón Comunitario no quedara restringido al dominio de una sola familia, y que progresivamente funcionara como un espacio común del que todos los habitantes del barrio pudieran sentirse parte.

Ahora bien, tres años después de mi ingreso al Proyecto, los acontecimientos que se desataron con la inundación representarían un punto de inflexión en nuestro hacer extensionista y a su vez en mi rol en el barrio. A las actividades cotidianas que desde el Proyecto veníamos desplegando hasta entonces, se sumó nuestra participación en el conflicto que emergió en torno a la obra sobre el arroyo El Gato y al proyecto de relocalización. A partir del desarrollo de esta obra, nos involucramos activamente en algo de lo que no habíamos participado antes en el barrio: una demanda colectiva. Asimismo, este conflicto representó un punto de inflexión en mi inserción en el campo, ya que se convirtió rápidamente en el objeto de una investigación etnográfica que

perspectivas sobre esta función universitaria. Por un lado, la extensión entendida como "transferencia": esta es la mirada clásica que concibe a la extensión como una relación unidireccional donde el conocimiento y la producción de saberes son exclusividad de la universidad que los "transfiere" a la sociedad. Por otro lado, la extensión es concebida como "territorialización" de la universidad (Trinchero y Petz, 2014) y como "circularidad dialéctica" (Manzano, 2019) o "hibridación" (Vaccarezza, 2015) de conocimientos. Desde esta mirada, la extensión se percibe como la intervención y producción de saberes en forma conjunta con la sociedad, a partir de un "diálogo" o de una "reciprocidad" (Fuentes, 2016), "atendiendo a las demandas, intereses y necesidades de la misma" (Pinedo y Diaz, 2016: 3). 
desarrollé para la elaboración de mi tesis doctoral, asumiendo un doble rol: como etnógrafa y como extensionista.

\section{Seguir el conflicto}

El conocimiento previo del campo que la extensión me habilitaba, y aquel diagnóstico sobre las dificultades para la consolidación de la organización en el barrio, me condujeron a enfocar la atención etnográfica sobre este conflicto que se tramaría en torno a una demanda colectiva por hábitat. El avance de la obra de ampliación del arroyo y las inminentes consecuencias que ello tendría para el barrio, o al menos para las viviendas ubicadas más próximas al canal, alarmarían a los vecinos. Por entonces, el conflicto se iniciaba cuando comenzaron a circular por Las Quintas rumores de una posible relocalización, y sin embargo ningún funcionario o autoridad responsable de la obra se había acercado a informar o participar a los habitantes al respecto. Como ha estudiado la bibliografía, la falta de participación de los usuarios en los programas de urbanización y de construcción de viviendas en los barrios populares ha sido una constante en las modalidades de intervención del Estado argentino en materia habitacional (Cravino, 2017), incluso a pesar de los grandes cambios que representó la nueva política habitacional implementada a nivel nacional a partir del año 2003 (Ferraudi Curto, 2014).

En este contexto de incertidumbre, los miembros del Proyecto de extensión intentaríamos obtener información oficial sobre la posible relocalización, y para ello solicitamos una entrevista con un funcionario del Ministerio de Infraestructura. Este será el comienzo de un reclamo que surge inicialmente motivado por la búsqueda de información, y que irá progresivamente disputando las condiciones mismas de la relocalización, y en definitiva, se convertirá en un reclamo por un hábitat digna para los habitantes de Las Quintas.

A partir de ello se irán entramando un conjunto de actores que no conformaban previamente una organización colectiva como tal, sino que se irán asociando en el proceso mismo de reclamar (Melé, 2016). Esta red de actores híbrida articularía a los habitantes del sector qom del barrio, pero también a los vecinos del sector paraguayo, a los miembros del proyecto de extensión, a los referentes de una organización territorial local, y a los miembros de un colectivo de abogados. 
Ser parte del proyecto de extensión y tener inserción en el barrio en el momento en que surgió este conflicto me permitiría seguirlo etnográficamente desde sus inicios y durante todo su desarrollo (concentrando el trabajo de campo especialmente entre 2014 y 2015). El conflicto se convirtió en el objeto de la investigación que llevé adelante desde un enfoque construido en el cruce entre etnografía y pragmatismo.

Los aportes de la sociología pragmática francesa, especialmente del campo de estudios sobre acciones de denuncias y movilizaciones colectivas (Boltanski, 2000; Cefaï, 2009, 2011), me permitían estudiar esta red de actores que se iba construyendo en torno al reclamo, partiendo de no asumir la unicidad a priori de este colectivo, y rastreando en cambio las acciones de asociación que lo hacían emerger.

En el campo de estudio de las acciones colectivas, este enfoque se corre de "las posiciones que sugieren una armonía preestablecida entre las orientaciones de los actores (los enfoques estructuralistas) o un mecanismo invisible de coordinación (los enfoques individualistas que presuponen elecciones racionales)" (Potthast, 2019: 405). Asimismo, propone el abandono de las concepciones sustancialistas y naturalistas de los grupos sociales, desplazando en cambio la atención hacia las situaciones problemáticas (Cefaï, 2011) en las que éstos se constituyen, hacia el trabajo social de definición y delimitación de los grupos sociales (Boltanski, 2015), atendiendo a las acciones que les han dado forma y visibilidad. Antes que probar con modelos preestablecidos que expliquen las motivaciones y orientaciones de la acción colectiva a priori, los autores de esta corriente proponen que se debe describir y comprender "la situación problemática a la que las personas están confrontadas y qué las lleva en un momento dado a comprometerse en una acción colectiva" (Cefaï, 2011: 140).

Por otra parte, este enfoque ha contribuido sustantivamente al estudio de las acciones colectivas de reclamo en términos de las capacidades para la instalación de denuncias en el espacio público teniendo en cuenta las competencias de los actores para la crítica, lo que supone la elaboración de argumentos, el trabajo de generalización de la denuncia, la superación de pruebas (Boltanski, 2000). Como sostiene Potthast (2019: 390), “dados un alto nivel de incertidumbre y el hecho de que el orden social implica tensiones y fricciones, este enfoque sostiene que los actores poseen capacidad crítica y están dispuestos a involucrarse con el orden social como una realidad por criticar".

Poner la mirada en las prácticas situadas nos permite correr la atención de los actores colectivos como sujetos pre-constituidos hacia los procesos intersticiales de asociación 
y formación de grupos; superar el análisis de los motivos de la acción política en términos de la deliberación racional y reponer en cambio los compromisos que conducen a los actores a participar en acciones colectivas. $\mathrm{Y}$ es precisamente la etnografía, al decir de Cefaï et al. (2012), la que permite acompañar los momentos de emergencia de una participación no programada o espontánea, dar cuenta de los procesos de adquisición de capacidades políticas, atender a los modos de participación que exceden a los canales instituidos, e incluso comprender los sentidos del rechazo a participar.

En el proceso de investigación, y a medida que me involucraba en las acciones de reclamo que iban tomando forma en Las Quintas, comencé a poner en acto una etnografía que no era sólo el método con el que llevaba adelante el trabajo de campo, sino que era también el enfoque con el que buscaba comprender el conflicto (Guber, 2011; Peirano, 2014). La etnografía como enfoque remite a la interpretacióndescripción del mundo social que estudiamos, la que "proviene de la articulación entre la elaboración teórica del investigador y su contacto prolongado con los nativos" (Guber, 2011: 18). Desde este punto de vista, no se trata del método que precede a la teoría, sino que posee en sí misma un carácter teórico, en la medida en la que nos permite confrontar la teoría con nuevos datos, y transformar así los puntos de vista teóricos preexistentes (Peirano, 2014). Como sostiene Cefaï (2013: 27), la etnografía construye teoría de una manera no dogmática, "en una dinámica que vincula las preguntas con los métodos que elegimos, los datos que recogemos y los problemas que resolvemos".

El enfoque construido entonces en base a la etnografía y al pragmatismo fue condensado en la investigación en lo que llamé seguir el conflicto, en las acciones que lo configuraron y en las escalas temporales y espaciales que fue atravesando en su desarrollo. Asimismo, esto fue posible por el doble rol asumido en el campo, como etnógrafa y como extensionista. Gracias a mi inserción en el Proyecto de extensión, uno de los actores de la trama estudiada, pude participar de asambleas con los vecinos en el barrio, de reuniones con funcionarios, de "mesas chicas" de coordinación con otros actores de la red, de encuentros en el marco del Consejo Social de la Universidad donde se llevaron a cabo las negociaciones, de recorridos por la ciudad para evaluar destinos posibles para la relocalización. 
En el siguiente apartado describo empíricamente esta articulación entre etnografía y extensión, concentrándome en la reconstrucción de una de las modalidades centrales en las que se dio la participación del Proyecto en el conflicto: a partir de la elaboración de un relevamiento de los vecinos afectados por la obra.

\section{Segunda parte: la intervencón extenionista en el conflicto.}

El conflicto se inició a mediados de 2014, como sostuve en el apartado anterior, en un clima de incertidumbre ocasionado por la falta de información respecto a la obra de ensanchamiento del arroyo y a las futuras consecuencias de la misma para el barrio. En este escenario, las primeras acciones que darían lugar al reclamo ante los funcionarios del Ministerio de Infraestructura se concentraron en la búsqueda de información oficial y precisa sobre la aparente relocalización de la que por entonces sólo circulaban rumores.

En estos primeros pasos, que consistieron en la realización de algunas entrevistas con funcionarios y de asambleas con los vecinos del barrio, comenzaron a articularse un conjunto de actores que luego protagonizaría el reclamo colectivo: como mencioné anteriormente, los habitantes de ambos sectores de Las Quintas, los miembros del Proyecto de extensión, el referente de una organización territorial, el Movimiento Justicia y Libertad (MJyL), y los abogados del Colectivo de Investigación y Acción Jurídica (CIAJ).

De los diálogos mantenidos con los funcionarios a cargo del proyecto de relocalización, esta red de actores pudo comprender que los datos sobre cuántas y cuáles viviendas debían ser removidas para el avance de la obra iban siendo construidos "sobre la marcha" (como reconoció uno de los funcionarios), a medida que ésta avanzaba: el área de hidráulica del Ministerio, a cargo del desarrollo técnico, comunicaba paulatinamente la información sobre las casas que obstaculizaban la ampliación del canal al área de Vivienda, a cargo de la relocalización. Esto implicaba que, a pesar de que las máquinas excavadoras se encontraban por entonces ya a pocos metros del barrio, los funcionarios de Vivienda aún no tenían precisiones respecto a qué familias debían ser relocalizadas.

La posibilidad de negociar las condiciones de la relocalización se construirá en parte gracias a la consolidación de la red de actores como reclamantes (Best, 1990; Boltanski, 2000). No se trataría sólo de un grupo pequeño de vecinos afectados, sino de un 
colectivo integrado por otros actores de peso en el ámbito local, como eran el MJyL, el CIAJ, y la Universidad. Asimismo, no se trataría sólo de relocalizar a seis u ocho viviendas, como sostuvo uno de los funcionarios, sino de todas aquellas que se encontraran igualmente afectadas por la obra: ya sea por el recorte en los terrenos que el ensanchamiento del arroyo implicaba, por las roturas de paredes de las casas más próximas producidas por las excavaciones de tierra, o por los riesgos de quedar ubicadas al borde de un profundo canal de cemento. En la medida en que la relocalización comenzó a ser vista como la oportunidad para los vecinos de obtener por parte del Estado viviendas de mejor calidad y con los títulos de propiedad con los que no contaban en Las Quintas, el reclamo se orientó hacia la búsqueda por ampliar el número de afectados por la obra.

En este proceso, el Proyecto de extensión tuvo un papel relevante en la medida en que puso en acto ciertos saberes disciplinares en la construcción de un relevamiento en el barrio, que sirvió como argumento y legitimación del reclamo. No pretendo aquí describir el desarrollo del conflicto, ni las distintas acciones llevadas a cabo por los actores de la red, lo que ha sido abordado en otros trabajos, sino concentrarme en este evento particular que me permitirá reflexionar sobre la articulación entre etnografía y extensión.

\section{$\underline{\text { El relevamiento }}$}

La idea de realizar un relevamiento en Las Quintas para conocer de primera mano cuántas viviendas realmente estaban siendo o serían afectadas por el ensanchamiento del canal surgió durante una de las asambleas barriales. Ese día, varios vecinos habían relatado que sus viviendas comenzaban a sufrir roturas de paredes por los movimientos de las máquinas excavadoras en el canal. Mientras tanto, circulaban rumores de que en otros barrios de la ciudad también asentados sobre el margen del arroyo El Gato los funcionarios del Ministerio habían llevado a cabo censos para determinar la cantidad de viviendas afectadas; sin embargo esto no había sucedido en Las Quintas.

Ante esta falta de información precisa sobre la situación del barrio, y la necesidad de construir herramientas para consolidar el reclamo ante los funcionarios, la red de actores se dispuso a llevar a cabo un relevamiento propio. El cuestionario fue elaborado inicialmente por los abogados del CIAJ, quienes podían prever qué tipo de información podía llegar a ser útil en el eventual caso de una presentación judicial por el tema. 
Luego, los miembros del Proyecto de extensión que proveníamos de Sociología, haciendo uso de cierto conocimiento específico sobre este tipo de técnicas de investigación, ajustamos algunas preguntas.

El cuestionario quedó conformado por tres grupos de interrogantes. El primero relevaba información personal. Este conjunto incluía preguntas sobre el lugar de origen, la pertenencia a una "comunidad o pueblo originario", el estado de salud, el nivel de educación y la situación laboral de los miembros de la familia. El segundo grupo correspondía a "información habitacional". En este grupo, las preguntas interrogaban sobre el tiempo de residencia en el barrio, la situación habitacional de la familia: si la vivienda era "alquilada", "prestada", "casilla propia" o "terreno propio", si poseía algún documento respaldatorio de esta situación, de qué material estaba mayormente construida, si se le habían hecho mejoras en los últimos años, cuántas habitaciones poseía y si contaba con baño al interior de la misma. Finalmente, el tercer grupo de preguntas estaba orientado a la "información referida a la posible relocalización". Aquí, los interrogantes incluían: si la persona o algún miembro de la familia había sido participado del proyecto de obra, si se le había requerido opinión sobre la misma, si había sido informado -formal o informalmente- de una posible afectación por la obra, si la persona creía que se vería afectada, y finalmente, si se le plantearon propuestas concretas de relocalización.

Este cuestionario sería complementado con una localización georeferenciada de las viviendas: es decir, ubicaríamos en una imagen satelital del barrio las distintas viviendas encuestadas. Para ello, y considerando que las casas se encontraban muy próximas unas a otras, lo que volvía difícil la tarea de distinguirlas simplemente a partir de identificar sus respectivos techos en la imagen satelital, nos propusimos elaborar, luego de finalizada cada encuesta, un pequeño dibujo a mano alzada con referencias de la ubicación de la vivienda, que nos sirviera posteriormente para ubicarla en el mapa general del barrio.

El relevamiento fue realizado en cuatro instancias, por parte de nueve integrantes del Proyecto de extensión en total entre las cuatro jornadas. Además, fuimos acompañados por algunas vecinas del barrio que realizaron junto a nosotros el recorrido por las viviendas. En total se realizaron 58 encuestas. Aquí me concentraré en los resultados obtenidos en el tercer grupo de interrogantes. 
Las respuestas sobre la información que poseían los vecinos relativa a la posible relocalización eran homogéneas y rotundas: ninguna persona de todas las familias encuestadas había sido invitada a participar del proyecto de obra de ampliación del arroyo o se le había requerido opinión sobre el mismo. De las 13 personas que dijeron haber sido informadas respecto a una posible afectación de sus viviendas, sólo 4 indicaron que esta información provino de parte de algún funcionario público. El resto señaló que los rumores provenían mayormente de parte de otros vecinos. La encuesta confirmaba entonces lo que había comenzado a tramarse desde el anuncio de la obra y que era el puntapié inicial del reclamo: el clima de incertidumbre y desinformación sobre la obra y la posible relocalización.

Ahora bien, la encuesta también tuvo cierto carácter performativo, ya que del total de encuestados, 38 personas dijeron creer que sus viviendas se verían afectadas por la obra. Esto contrasta con la pequeñísima cantidad de personas que efectivamente habían sido informadas respecto a una posible relocalización. El hecho de que las máquinas excavadoras ya se encontraran ensanchando el canal a pocos metros de las viviendas, en un clima de incertidumbre generalizado, contribuyó claramente al temor de los vecinos en relación a sus posibles consecuencias. Pero si había quienes no se habían preocupado o confiaban en que sus viviendas no correrían peligro, el hecho de que un grupo de personas externas al barrio, provenientes "del centro" de la ciudad, con planillas, recorrieran casa por casa preguntando por la relocalización, contribuyó al menos a plantar la duda.

\section{Grados de afectación}

Luego de haber realizado el relevamiento, los miembros del Proyecto procesamos las respuestas obtenidas y volcamos esa información sobre la imagen satelital del barrio, mediante íconos de colores sobre cada una de las viviendas encuestadas. Para ello elaboramos una clasificación de acuerdo a distintos "grados de afectación". Los que señalamos como "fucsias" y "rojos" correspondían al grado mayor de afectación, y se trataba de 4 casos a quienes se les había dicho que debían relocalizarse ("fucsias") y otros 15 casos que se ubicaban igual de próximos al arroyo o ya habían sufrido daños en sus viviendas ("rojos"). El resto de los casos encuestados, identificados como "amarillos", si bien en un grado menor que los anteriores, fueron también elaborados como "afectados". Para ello, los miembros del Proyecto definimos una serie de 
conceptos que -desde una noción ampliada de afectación- caracterizaban los modos en los que esos vecinos estaban siendo perjudicados por la obra: por la "desinformación", la "inseguridad" (por la cercanía de las máquinas excavadoras a las viviendas que generaba riesgos cotidianos), y el "miedo" (ante la incertidumbre y las posibles consecuencias de la obra).

La construcción de distintos "grados” en los que los vecinos de Las Quintas estaban siendo perjudicados por la obra permitió dar forma a un nuevo criterio de afectación: si para las funcionarios, la definición de las viviendas a remover para el avance de la obra estaba dada por lo que los aspectos técnicos de la misma fueran requiriendo, y esto en principio parecía señalar a cuatro viviendas, los actores de la red comenzarían a discutir ese número. El relevamiento sería la base sobre la cual fundar esa disputa y argumentar a favor de la ampliación del número de afectados.

\section{Tercera parte: la escritura como punto de encuentro entre la extensión y la etnografía}

El evento narrado en el apartado anterior echa luz sobre una dimensión concreta en la que etnografía y extensión se articulan. La etnografía, como sostienen Guber y Peirano, es enfoque, es método y también es texto. Este texto, al decir de Cefaï (2013), se trama en una "cadena de escrituras" que va de la toma de notas de campo, a la constitución de un diario, y luego al trabajo de descripción, análisis e interpretación de ese corpus de datos. Aquí, sostendremos que la escritura es el punto de encuentro entre dos modos de estar y hacer en el campo, el de la extensión universitaria y el de la investigación etnográfica, que se plasma como intervención, como registro y como interpretación.

\section{Escritura como intervención}

Como vimos con el relevamiento, la escritura es utilizada desde la extensión como herramienta de intervención en base a un saber hacer específico. Este saber, derivado en parte de la formación profesional, se actualiza en prácticas de intervención concretas, que se ensayan, se ponen a prueba.

Luego de sistematizados los datos del relevamiento, los miembros del Proyecto escribimos un documento que plasmaba sus resultados. Este extenso documento, titulado "Informe preliminar sobre la situación de las familias afectadas por las obras de ampliación del arroyo El Gato", describía el recorrido realizado hasta el momento en 
el reclamo y detallaba las distintas dimensiones de la afectación construidas a partir del relevamiento, incluyendo el mapa con la clasificación. El informe señalaba como "afectaciones directas", desde los daños materiales sufridos en las viviendas y/o terrenos por el avance de la obra hasta la exposición a riesgos y la "violencia provocada por la intrusión de trabajadores en sus terrenos y la cercanía de las máquinas”. Pero también mencionaba una serie de afectaciones generales a todos los vecinos encuestados que se relacionaban con los posibles perjuicios ocasionados por la relocalización de algunas familias en otro barrio. Entre ellas, se mencionaban: "daños socio-comunitarios y familiares provocados por el desmembramiento de hogares que, si bien viven en distintas viviendas, comparten la organización de la vida cotidiana, el cuidado de los niños y ancianos y la obtención de recursos económicos fundamentales para su supervivencia". La referencia a prejuicios para la "comunidad" estaba relacionada al intento por instalar la ampliación de la noción de "afectación", rechazando la idea de que se trataba de un problema de unos pocos vecinos.

En esta misma línea, la frontera entre vecinos qom y vecinos paraguayos que, como mencioné, operaba en las distintas identificaciones de los habitantes de Las Quintas con espacios diferenciados al interior del barrio, no operó como elemento distintivo en la manera en que los miembros del Proyecto de extensión elaboramos los resultados del relevamiento: el objetivo para legitimar la existencia de un conflicto a ser resuelto sería mostrar la gran cantidad de vecinos afectados. Para ello, cobraba relevancia la fuerza del número y perdía sentido mostrar las divisiones al interior del barrio.

Este informe sería escrito con la intención no sólo de plasmar los resultados del relevamiento en un documento que pudiera ser distribuido entre los actores involucrados, sino también de ser difundido públicamente para dar a conocer el conflicto en Las Quintas, con la expectativa de que el reclamo adquiera "publicización" (Cefaï, 2014).

La información construida mediante el relevamiento y plasmada en el informe no fue puesta en duda o cuestionada por ninguno de los actores, en ninguna de las instancias de negociación, y se convirtió rápidamente en una herramienta legítima. Esta legitimidad estuvo dada, en parte, por la técnica en sí misma (planillas, números, mapas que se vuelven incuestionables). Desde el campo de estudios norteamericanos sobre la construcción de los problemas públicos, Gusfield (1981) y Best (1990) llaman la atención sobre los modos de conceptualizar la utilización de evidencia científica que 
suelen hacer los actores involucrados en la construcción de un reclamo como problema público. Esta evidencia, sostienen los autores, no debe ser concebida simplemente como evidencia objetiva, sino como dimensión misma de la retórica del reclamo, es decir, como parte de los esfuerzos realizados por los actores para persuadir, para volver convincente su reclamo. Entre los elementos centrales que comúnmente conforman la retórica de construcción de reclamos, Best identifica la utilización de "ejemplos tipificadores" y “estimaciones numéricas" o estadísticas (1990: 24). Los datos elaborados a partir del relevamiento -las condiciones generales de vida de las familias, la cantidad de viviendas emplazadas sobre el margen del arroyo que eran afectadas en un sentido amplio por la obra, el número de encuestados que declararon haber sufrido daños en sus techos o pisos, pérdidas en sus terrenos- todo esto sumado a la representación visual de la cercanía al arroyo plasmada en la geo-referenciación de las encuestas sobre una imagen satelital del barrio, se constituyó en una evidencia sólida sobre la que se fundamentó la necesidad de ampliar el número de quienes se consideraban "afectados" por la obra, y por lo tanto, sujetos de compensación por parte del Ministerio.

Para una concepción extendida sobre el Estado moderno, la "legibilidad" (Scott, 1998) es una función clave del ejercicio de gobierno. Desde esta noción, se entiende que el Estado construye información, mide, clasifica, cuantifica a la sociedad para volverla legible y organizar a la población de maneras que simplifican sus funciones clásicas de tributación, conscripción y prevención de la rebelión (Scott, 1998: 2). Por otra parte, esta noción de que en la dicotomía Estado y sociedad como dos esferas escindidas, corresponde exclusivamente al primero la medición sobre la segunda, ya ha sido discutida de manera clara (Manzano y Moreno, 2011). Como sostienen Virginia Manzano y Lucila Moreno, en muchas ocasiones "el manejo del lenguaje censal asociado al Estado es dinamizado por personas que toman parte de acciones colectivas. [Este lenguaje es] incorporado para fundamentar demandas y favorecer la apertura de espacios de negociación con el Estado" (2011: 3). En nuestro caso, el relevamiento fue elaborado, antes que a partir de un aprendizaje de las técnicas censales propias de las mediciones que habitualmente los organismos del Estado realizan sobre los sectores populares, más bien por las tradiciones disciplinares y prácticas profesionales de los miembros del Proyecto de extensión y del CIAJ, que hicieron de base a la elaboración y 
aplicación de la encuesta. Y al igual que sostienen Manzano y Moreno (2011), este dispositivo se convirtió en una herramienta para fundamentar la demanda.

\section{Escritura como registro}

La escritura no fue solo herramienta de intervención "hacia fuera" por parte de los miembros del Proyecto, sino también fue una práctica llevada adelante cotidianamente "hacia adentro", con el fin de registrar nuestro hacer extensionista. Y en esta modalidad, la escritura como registro también emparenta a la extensión con la etnografía.

Los registros sistemáticos de nuestras actividades de extensión semanales, así como de los eventos de los que participamos en el marco del reclamo por la relocalización, tenían tres objetivos. El primero y más inmediato era el de comunicar a los demás miembros del Proyecto los acontecimientos más recientes en el barrio en relación al conflicto o al desarrollo de las actividades semanales. El correo electrónico o los mensajes de Facebook (y más tarde el WhatsApp), eran los medios utilizados para "ponernos al día", a partir de registros detallados elaborados por quienes habían participado de los talleres, asambleas o reuniones de esa semana. El segundo objetivo, a mediano plazo, era el de que esos registros sirvieran de información para la elaboración de los informes anuales que el Proyecto debía presentar a las instancias de evaluación del área de extensión de la Universidad. En tercer lugar, a largo plazo, se esperaba que constituyesen la base de futuras sistematizaciones (Jara Holliday, 2018) sobre nuestra práctica extensionista que nos permitieran producir conocimiento sobre la misma ${ }^{4}$. Algo que requería un mayor esfuerzo en términos de disposición y de tiempo, lo que hizo que se conviertiera quizá en el objetivo más postergado.

El registro extensionista se articuló, durante el conflicto, con el registro etnográfico: durante el desarrollo de la investigación, registré en mi diario de campo todos los acontecimientos, asambleas, reuniones, conversaciones de los que participé (registros que, como mencioné antes, también compartí con el resto de los miembros del Proyecto). Pero además incorporé a este diario como "huella documentaria" (Cefaï,

\footnotetext{
${ }^{4}$ La sistematización de experiencias es una propuesta que surge en América Latina en los años 60 y 70 , vinculada a otras en la región como fueron la educación de adultos, la educación popular, el paradigma de la investigación-acción o la teología de la liberación (Jara Holliday, 2018). Se plantea como una práctica de registro, descripción e interpretación de la experiencia de intervención en distintos ámbitos populares (como la educación, el trabajo social o la extensión universitaria) con el objetivo de producir un conocimiento crítico que revalorice la vinculación práctica con un territorio o una población determinada. Asimismo, se espera que ese conocimiento producido en base a la experiencia de intervención contribuya a modificar o mejorar dicha práctica.
} 
2013) otros textos que no eran de mi autoría y que completaban los datos de campo a analizar: aquellos registros, relatos breves, mensajes o comunicaciones que otros miembros del equipo elaboraron y compartieron en relación al conflicto. De este modo, los registros cotidianos que realizamos como equipo de extensión durante nuestra intervención, se constituyeron en datos etnográficos.

\section{Escritura como interpretación}

Por último, la escritura como punto de encuentro entre la extensión y la etnografía toma también la forma de interpretación. El texto etnográfico no es ni copia objetiva de la realidad, ni ficción literaria o mera construcción textual para persuadir audiencias: es un argumento o interpretación fundada (Guber, 2011; Cefaï, 2013). En este sentido, esta etnografía como argumento fue elaborada en base al diálogo entre los datos del campo y el enfoque teórico y epistemológico de la sociología pragmática. Y asimismo, fue posible gracias al ejercicio de reflexividad (Guber, 2014) necesario para convertir en dato etnográfico mi particular inserción en el campo, como etnógrafa y extensionista.

Haber llevado adelante esta etnografía no sólo como investigadora o tesista, sino también como extensionista, me impuso un doble desafío en términos metodológicos. El Proyecto de extensión no fue sólo el espacio desde el cual me inserté en el barrio y llevé adelante el trabajo de campo, sino que fue también un actor de la trama analizada. Esto implicó la búsqueda por desnaturalizar las propias prácticas y sentidos de la intervención en el cruce entre extensión e investigación, y a su vez, la posibilidad de problematizar y conceptualizar modalidades nativas concretas de la práctica extensionista.

En principio, una inserción de este tipo brinda una posibilidad inigualable de acceso a las tramas de interacción bajo análisis y de compartir los códigos y lenguajes del campo. Como sostiene Borges (2003: 44), en el campo etnográfico, los extraños o extranjeros no son sólo aquellos que vienen de afuera, sino centralmente aquellos que no comparten los códigos, el lenguaje del lugar. Estar en el campo siendo parte activa de él como extensionista me permitió aprender desde un inicio sus códigos e ir compartiendo el lenguaje específico que se iría constituyendo en el proceso. Pero también, esta inserción pudo -mediante un necesario ejercicio de reflexividad- volverse dato etnográfico sobre el mundo de prácticas y sentidos estudiado. 
Si bien en términos generales los miembros del Proyecto inscribiríamos nuestra intervención en la perspectiva del diálogo y la coproducción de saberes en la interacción (Manzano, 2019) con los habitantes del barrio, la puesta en práctica de esta manera de concebir la extensión, no estuvo libre de tensiones y dilemas. La reflexividad funciona entonces como herramienta a través de la cual intentaré convertir estas tensiones del campo en datos etnográficos que me permitan captar algo de las lógicas de las dinámicas de interacción en las que participé como extensionista e investigadora.

Para los miembros del Proyecto, cuya intervención en Las Quintas siempre estuvo volcada a la realización de talleres (de acompañamiento escolar, lectura y psicología comunitaria con niños, de producción de videos y música con jóvenes, de tejido con mujeres), la preocupación y duda respecto a la utilidad o inutilidad de dichas actividades para el barrio estaba siempre presente. Sus efectos eran difusos. Si bien el afecto y el reconocimiento de muchos vecinos nos confirmaban cotidianamente que teníamos un lugar en el barrio que valía la pena sostener, creíamos que los frutos de dicha intervención, de existir, se verían con el tiempo, a largo plazo. Finalmente, la emergencia de un reclamo colectivo del cual formábamos parte como Proyecto de extensión, y en el que habíamos tenido un rol central a partir del relevamiento, nos habilitaba la percepción de que por primera vez nuestro accionar en el barrio tenía "resultados" claros, directos e inmediatos.

Pero en esta intervención nos enfrentaríamos a ciertas tensiones o dilemas que podrían presentarse sintéticamente del siguiente modo: a) conducir vs. acompañar; b) perseguir metas de largo alcance vs. sostener actividades cotidianas; c) llevar adelante intervenciones paliativas vs. lograr soluciones a problemas reales.

a) Como sostuve al comienzo, una de las dificultades principales que los referentes del barrio nos expresaban con frecuencia para explicar los obstáculos encontrados en el intento por garantizar la vigencia de la Asociación Civil ante el Instituto Nacional de Asuntos Indígenas, radicaba en la inasistencia de la mayoría de sus vecinos a las asambleas convocadas por ellos. Ante esta situación, en numerosas ocasiones nos solicitaron que fuéramos los miembros del Proyecto los que convocáramos a dichos encuentros, confiando en que nuestro reconocimiento en el barrio por parte de los vecinos garantizaría una mayor participación. No obstante, siempre consideramos mejor no involucrarnos en esa tarea. ¿Por qué? Por un lado, porque si bien nuestro ingreso al barrio y nuestro vínculo más cercano fue siempre con estos referentes, conociendo los 
conflictos internos existentes preferíamos no "tomar partido" por algunas familias. Colaborar con la tarea que nos solicitaban, posiblemente sería percibido de esa manera por muchos de los vecinos. Por otro lado, porque considerábamos que podíamos colaborar o asistir en el desarrollo de este tipo de acciones, pero que no debíamos protagonizarlas. Nuestra función, imaginábamos, debía ser la de acompañar el desarrollo de procesos de organización, pero sin asumir roles de conducción de los mismos. Y ser quien convocara a las asambleas, pensábamos, nos pondría inevitablemente en ese lugar.

Ahora bien, esta tensión continuó atravesándonos y nuestro accionar al respecto se fue transformando con las circunstancias. Cuando a finales del año 2013 nos llegaron los rumores acerca de un proyecto de relocalización que afectaría al barrio, las dos primeras acciones llevadas a cabo fueron la realización de una entrevista con un funcionario del Instituto de la Vivienda, de la que sólo participamos tres miembros del Proyecto, y una asamblea para la cual hicimos circular volantes de invitación en el barrio durante los días previos. Si bien sería ilusorio creer que el Proyecto "condujo" inicialmente este reclamo -aún más considerando que inmediatamente comenzó a conformarse una red que involucraría a actores de gran peso en el barrio y en el ámbito público local (el MJL, el CIAJ, el Consejo Social de la universidad)- sí es cierto que la tensión fue para muchos de nosotros más palpable que nunca. Por fin presenciábamos la emergencia de un escenario que habilitaba una acción colectiva de reclamo en el barrio, y nos encontrábamos tomando la palabra en asambleas o reuniones organizadas por nosotros mismos, instando a los vecinos a que se organicen.

b) Por otro lado, pretender perseguir un objetivo de esa magnitud, desde la intervención de un proyecto de extensión con no más de quince o veinte miembros, cuyo financiamiento alcanzaba para solventar los gastos básicos y sostener las actividades, pero que - como todos los proyectos de extensión- se sostenía a base del trabajo voluntario de sus integrantes, nos imponía además otro dilema: aquel que se juega en una economía de esfuerzos. ¿Cómo equilibrar la persecución de metas de más largo alcance en el barrio, con el esfuerzo y desgaste que implica el sostenimiento de las actividades y la presencia cotidiana en él? En muchas ocasiones los objetivos más amplios se hacían lejanos y parecía devorarnos la vorágine del día a día de los talleres: la asistencia intermitente de sus participantes, el desafío constante y no siempre satisfecho de proponer contenidos que les interesen, que los diviertan, que los inviten a 
involucrarse, e incluso las dificultades prácticas con las que muchas veces nos encontrábamos -por ejemplo, que circunstancialmente no hubiese electricidad en el Salón Comunitario-.

Ante el escenario de conflicto, esta tensión se expresó inicialmente en el hecho de que las acciones de reclamo que comenzamos a llevar adelante desde el Proyecto nos involucraron, a casi todos los miembros del mismo, en nuevas tareas que se sumaban repentina y velozmente a las que cada uno ya desarrollaba en sus respectivos talleres semanales. Las entrevistas con funcionarios, las asambleas en el barrio, el relevamiento, demandaron la participación de la gran mayoría de los miembros del Proyecto, que comenzaron a asumirla cada uno en la medida de sus posibilidades. Pronto se hizo evidente que, con la magnitud que el conflicto iba ganando, no sería posible para todos sostener a la par ambas tareas. Ante esta situación, se tomó la decisión colectiva de que algunos nos abocáramos exclusivamente a seguir el reclamo. La práctica de los registros cotidianos habilitaron que pudiéramos dividirnos las tareas, y que quienes seguíamos el conflicto por la relocalización fuéramos informando sobre su devenir al resto de los miembros del Proyecto. Esos espacios de comunicación escrita a través de las plataformas digitales se convirtieron también en instancias de discusión o debate sobre cómo proceder.

c) Por último, más allá de la creencia en la utilidad de los talleres que desarrollábamos en el barrio, ésta se nos aparecía muchas veces difusa, pequeña, minúscula al lado de las enormes carencias materiales y dificultades cotidianas de los habitantes de Las Quintas. Los talleres ofrecían a los niños y jóvenes algunas horas fuera de casa junto a sus amigos y vecinos, un tiempo para leer, dibujar, escribir, cantar, actuar, filmar. Pero en las constantes reflexiones a las que esta intervención nos invitaba, aparecía muchas veces el escepticismo ante lo que inevitablemente se nos presentaba como un paliativo. ¿Qué función tiene -nos preguntábamos muchas veces-, de qué sirve, nuestra tarea en el barrio, si no contribuye directamente a mejorar las condiciones de vida de sus habitantes?

El conflicto habilitará para los miembros del Proyecto un camino en ese sentido. El reclamo para lograr la relocalización colectiva de muchos de los vecinos se nos apareció como la oportunidad para intervenir -quizá por primera vez- en la obtención de una solución concreta a uno de sus problemas cotidianos más apremiantes, como era el de la vivienda. "Creo que logramos lo que todo equipo extensionista se propone -había dicho 
la directora del Proyecto a pocos días de presentar el Informe producto del relevamiento- la incidencia en la resolución de problemas".

Ahora bien, esto nos pondrá en una encrucijada que hasta entonces habíamos logrado evitar. Los miembros del Proyecto nunca habíamos tenido que enfrentarnos a la compleja tarea de distribuir recursos materiales o económicos en el barrio. Sin embargo, el devenir del conflicto y nuestra interacción con los demás actores de la red nos conducirán a asumir un rol activo específico en la definición de los destinatarios de la relocalización: el relevamiento y la posterior construcción de grados de afectación de acuerdo a los datos obtenidos, conducirían prontamente a la elaboración de una "lista" de los vecinos que serían incluidos en la relocalización (y por lo tanto, que obtendrían una vivienda por parte del Estado). La conformación de esta "lista" nos llevaría a tomar decisiones respecto a la inclusión de los vecinos "más afectados" y por lo tanto también a la exclusión de muchos otros de esa oportunidad que representaba la relocalización.

Virginia Manzano (2019b: 57) relata su participación en la construcción de una pericia antropológica sobre movimientos sociales, y cuenta cómo en esa intervención experimentó "la tensión entre el conocimiento producido etnográficamente y las exigencias de veracidad y objetividad más propias del texto judicial”. Detrás de la "objetividad" del texto judicial elaborado, habían sido construcciones de sujeto "asimétricas, cotidianas, históricas y envueltas en relaciones de poder" (2019b: 57) las que le permitieron producir el conocimiento que sustentaba esa pericia. El manejo situacional de estas tensiones debería formar parte, sostiene la autora, de una "sistematización institucional de nuestras experiencias como antropólogas y antropólogos en esas arenas" (2019b: 57).

De modo similar en nuestro caso las estrategias de intervención en el reclamo variaron situacionalmente entre la distancia y la proximidad. Distancia cuando se percibía que era momento de legitimar el reclamo, y para ello se buscaba posicionar al Proyecto de extensión en un lugar "objetivo" (la construcción del relevamiento y del informe funcionaron en este sentido). Proximidad, en cambio, cuando se evaluaba que la cercanía, el conocimiento detallado de la situación de los habitantes del barrio que brindaba la experiencia concreta de trabajo cotidiano en el marco de la práctica extensionista, funcionaría como "prueba" (Boltanski, 2000) de los argumentos sostenidos en el reclamo (como sucedió por ejemplo durante las entrevistas mantenidas con funcionarios, en las que nos posicionábamos como actores que -a diferencia de 
ellos- conocían al barrio de primera mano). Distancia y proximidad se jugaron también en las formas en que nos relacionamos con los habitantes de Las Quintas durante el conflicto: la proximidad que nos conducía a intervenir en el reclamo para obtener colectivamente mejores condiciones habitacionales para los vecinos, y la distancia que buscábamos sostener cuando llegaba el momento de definir quiénes serían finalmente los beneficiarios.

La explicitación de estas tensiones y dilemas buscó objetivar mi lugar en el campo y el modo en que construí como dato etnográfico esta intervención desde un doble rol. Estas tensiones no sólo hablan de los modos en que se construye la intervención extensionista, sino también de cómo esa intervención iba siendo elaborada en la participación activa en el conflicto estudiado. Los dilemas entre conducir o acompañar, perseguir metas de largo alcance o sostener actividades cotidianas, llevar adelante intervenciones paliativas o lograr soluciones a problemas reales, echan luz sobre las formas en que se produce nuestra vinculación, como extensionistas y como etnógrafas, con las personas con quienes interactuamos en campo, y sobre las formas en que construimos conocimiento de esos vínculos.

\section{Conclusiones}

Este artículo exploró la articulación entre etnografia y extensión universitaria en un conflicto por hábitat en un barrio popular de la ciudad de La Plata. Para ello, describí el doble rol que asumí en este conflicto, como etnógrafa y como miembro de un Proyecto de extensión que se convirtió en uno de los actores de la trama estudiada.

Para los miembros del Proyecto, construir al actor reclamante y en ese proceso contribuir a la organización colectiva en el barrio era el objetivo tácito que orientó la intervención desarrollada. El hecho de haber formado parte de la trama de actores y acciones que seguí para esta etnografía no estuvo relacionado únicamente a la manera en la que accedí al campo (como integrante de uno de sus protagonistas). Explicitar los diagnósticos que los miembros del Proyecto teníamos acerca del barrio, los objetivos que nos proponíamos en relación a ello, y las actividades y tareas que desplegábamos para alcanzarlos, me permitió describir mejor cómo actuamos como parte de la red de actores del reclamo, cuáles fueron algunos de los motivos que lo impulsaron y cuáles las primeras modalidades que fue adoptando. El conflicto no sólo se "ajustó" a nuestros objetivos, intereses y práctica extensionista (en el sentido de que habilitó la acción 
colectiva que deseábamos para el barrio), sino que, además e inversamente, nuestros modos de hacer extensión (en articulación con la intervención de otros actores) configuraron el conflicto de determinadas maneras.

No quiero sostener aquí una mirada dicotómica que plantee que desde la etnografía produje conocimiento sobre el conflicto estudiado, y desde la extensión universitaria intervine en él. Como sostiene Pinedo (2020: 1), la extensión contribuye a la producción de un conocimiento en el ámbito universitario que está "en las relaciones entre las personas y entre las personas y los procesos que traspasan de un lado a otro las membranas que vinculan a la sociedad con la universidad”. En este artículo, ambos roles -el de la extensión y la etnografía- se dieron de modo articulado a inseparable en la producción de conocimiento: conocíamos en el proceso de intervenir, e interveníamos en función de ese conocimiento. Y una de las claves de esa articulación se plasmó en la escritura.

La posibilidad de construir conocimiento en función de esa doble inserción en el campo se conjugó con el desafío de desnaturalizar las propias acciones como parte integrante de la red del reclamo. Esto fue asumido a partir de la búsqueda por explicitar los dilemas, las incomodidades, las dudas que tuvimos como integrantes del Proyecto en nuestra intervención y sobre las que conversamos y reflexionamos cotidianamente a lo largo del proceso estudiado. La descripción y análisis de estas tensiones o dilemas, así como sostiene Guber (1995) sobre la reflexividad en torno a los "incidentes" generados en las situaciones de interacción en el campo, permiten echar luz sobre el objeto de estudio.

Por último, la reflexividad sobre esta intervención buscó también dar cuenta de un intercambio que la extensión propicia entre saberes que se construyen en los campos disciplinares universitarios y saberes que se construyen en las experiencias de habitar la periferia. Lejos de sostener una visión romántica de las posibilidades de esta articulación, es necesario reconocer que los contextos desiguales en los que estos intercambios se entablan imponen desafíos (los dilemas de la intervención como "conducir" o "acompañar", ilustran algunas de estas tensiones en nuestra propia práctica). No obstante, es posible sostener que hay formas de la intervención extensionista -como la que intentábamos llevar adelante en este caso- que se orientan por un deseo de potenciar el agenciamiento de los actores en el marco de una lógica de derechos (Manzano, 2019). En este caso, se trató de construir de manera conjunta un 
reclamo que pusiera en primer plano -en la negociación con los funcionarios- los propios saberes y criterios de los habitantes populares como saberes válidos, legítimos, para encontrar soluciones conjuntas al problema de la tierra y la vivienda, y a la vez, en esa operación, constituir una red de actores que se posicione como interlocutor válido ante el Estado. Convertir esta intervención específica en el conflicto como dato etnográfico supuso también dar cuenta de estos objetivos y deseos que nos motivaban, y los modos en que traducíamos esos motivos en prácticas de extensión universitaria.

\section{REFERENCIAS}

AUYERO, Javier; SWISTÚN, Débora. Inflamable: Estudio del sufrimiento ambiental. Buenos Aires, Paidós, 2008.

BEST, Joel. Threatened Children: Rethoric and concern about child-victims. Chicago, University of Chicago Press, 1990.

BOLTANSKI, Luc. Cómo se objetivó un grupo social: Los 'cuadros' en Francia, 19361945. Instersticios: Revista sociológica de Pensamiento Crítico, vol. 9, n. 2, pp. 75- 87, 2015 .

BOLTANSKI, Luc. El Amor y la Justicia como competencias: Tres ensayos de sociología de la acción. Buenos Aires, Amorrortu, 2000.

BORGES, Antonadia. Tempo de Brasilia: Etnografando lugares-eventos da política. Río de Janeiro, Relume Dumará, Núcleo de antropología de Política/UFRJ, 2003.

CEFAÏ, Daniel ¿Qué es la etnografía? Debates contemporáneos: Arraigamientos, operaciones y experiencias del trabajo de campo. Persona y Sociedad, vol. 27, n. 1, pp. 101-119, 2013.

CEFAÏ, Daniel, et al. Ethnographies de la participation. Participations, vol. 4, n. 3, pp. 7-48, 2012.

CEFAÏ, Daniel. ¿Cómo nos movilizamos? El aporte de un enfoque pragmático a la sociología de la acción colectiva. Versión castellana de: "Comment se mobilise-t- on? L'apport d'une approche pragmatiste à la sociologie de l'action collective". Sociologie et sociétés, n. 41/2, pp. 245-269, 2009. 
CEFAÏ, Daniel. Diez propuestas para el estudio de las movilizaciones colectivas: De la experiencia al compromiso. Revista de Sociología, vol. 26, pp. 137-166, 2011.

CEFAÏ, Daniel. Prólogo: Investigar los problemas públicos: con y más allá de Joseph Gusfield. En: J. Gusfield, La cultura de los problemas públicos: El mito del conductor alcoholizado versus la sociedad inocente. Buenos Aires, Siglo XXI, 2014.

CRAVINO, M. Cristina. La cuestión de la vivienda en el Área Metropolitana de Buenos Aires (2003-2008). Ciudadanías. Revista de Políticas Sociales Urbanas, vol. 1, pp. 3547, 2017.

FERRAUDI CURTO, M. Cecilia. Ni punteros ni piqueteros: Urbanización y política en una villa del conurbano. Buenos Aires, Gorla, 2014.

FUENTES, Sebastián. La extensión universitaria en Buenos Aires: Legitimidades y transformaciones recientes. Revista Ciencia, Docencia y Tecnología, vol. 27, n. 53, pp. 234-267, 2016.

GUBER, Rosana. Antropólogos nativos en la Argentina: Análisis reflexivo de un incidente de campo. Publicar, vol. 4, n. 5, pp. 25-46, 1995.

GUBER, Rosana. La etnografía: método, campo y reflexividad. Buenos Aires: Siglo XXI Editores, 2011.

GUBER, Rosana. Prácticas etnográficas: Ejercicios de reflexividad de antropólogas en campo. Buenos Aires, Miño y Dávila, 2014.

GUSFIELD, Joseph. The culture of public problems: Drinking-driving and the symbolic order. Chicago, University Chicago Press, 1981.

JARA HOLLIDAY, Oscar. La sistematización de experiencias: práctica y teoría para otros mundos posibles. Bogotá: Centro Internacional de Educación y Desarrollo Humano - CINDE, 2018.

MANZANO, Virginia; MORENO, Lucila. Censar, demandar y acordar: demandas colectivas y políticas estatales en el gran Buenos Aires". Revista Pilquen, v. 14, n. 1, pp. 133-143, 2011.

MANZANO, Virginia. La circularidad y producción relacional del conocimiento. En F. Brugaletta, M. González Canosa, M. Starcenbaum y N. Welschinger (Eds.), La política científica en disputa: Diagnósticos y propuestas frente a su reorientación regresiva 
(2019). La Plata: Universidad Nacional de La Plata. Facultad de Humanidades y Ciencias de la Educación; CABA, CLACSO, 2019.

MANZANO, Virginia. La construcción de una pericia antropológica sobre movimientos sociales populares: desafíos políticos, conceptuales y epistemológicos. Quehaceres. n. 4, pp. 48-58, 2019 b.

MELÉ, Patrice. ¿Qué producen los conflictos urbanos?. En: F. Carrión \& J. Erazo (Coord.), El derecho a la ciudad en América Latina: Visiones desde la política. (pp. 127-157). México, UNAM, 2016.

PEIRANO, Mariza. A favor de la etnografía. En: A. Grimson; G. Lins Ribeiro; P. Semán, La antropología brasileña contemporánea: Contribuciones para un diálogo latinoamericano. Buenos Aires, Prometeo, 2004.

PINEDO, Jerónimo; DÍAZ, Candela. Estrategias de gestión institucional para el desarrollo de la Extensión Universitaria en la Facultad de Humanidades y Ciencias de la Educación (FaHCE). Ponencia presentada en las $V$ Jornadas de Extensión del Mercosur, Tandil, 2016.

PINEDO, Jerónimo. La extensión universitaria como producción de conocimiento. Modalidades de articulación extensión-docencia-investigación. En F. Brugaletta, M. González Canosa, M. Starcenbaum y N. Welschinger (Eds.), La política científica en disputa: Diagnósticos y propuestas frente a su reorientación regresiva (2019). La Plata: Universidad Nacional de La Plata. Facultad de Humanidades y Ciencias de la Educación; CABA, CLACSO, 2019.

PINEDO, Jerónimo. Oficio, oficiantes y extensión universitaria Notas a favor de una sociología modesta en una universidad de poros abiertos. Cuestiones de Sociología, n. 21, 2020.

POTTHAST, Jör. La sociología de las convenciones y las pruebas. En: Benzecry, C.; Krause, M.; Reed I. A. (Eds.) La teoría social, ahora. Nuevas corrientes, nuevas discusiones. Buenos Aires: Siglo XXI Editores, 2019.

SCOTT, James. Seeing like a State: How certain schemes to improve the human conditions have failed. New Haven, Yale University Press, 1998. 
TRINCHERO, Héctor H.; PETZ, Ivannna. La cuestión de la territorialización en las dinámicas de integración universidad-sociedad: Aportes para un debate sobre el 'academicismo'. Papeles de Trabajo, n. 27, pp. 142-160, 2014.

VACAREZZA, Leonardo. Apropiación social e hibridación de conocimientos en los procesos de extensión universitaria. Cuestiones de Sociología, n. 12, 2015.

WRIGHT, Pablo. Ser-en-el-sueño: Crónicas de historia y vida toba. Buenos Aires, Biblos, 2008.

Recebido: $10 / 06 / 2020$

Aprovado: 04/09/2020 